\title{
Environmental Impacts of Hydropower and Alternative Mitigation Measures
}

\author{
Mohammed Mussa $^{1 *}$, Habtamu Teka ${ }^{1}$ and Hussein Ayicho ${ }^{2}$ \\ ${ }^{1}$ Department of Animal and Range Science, Madda Walabu University, Ethiopia \\ ${ }^{2}$ Department of Geography and Environmental Science, Madda Walabu University, Ethiopia
}

Received: 阱 April 12, 2018; Published: 制 April 20, 2018

*Corresponding author: Mohammed Mussa, Department of Animal and Range Science, Madda Walabu University, Ethiopia

\begin{abstract}
Hydropower is an important renewable energy resource worldwide. However, its development is accompanied with environmental drawbacks. The paper has reviewed the environmental drawbacks associated with hydropower projects. Change in hydrological flow regimes, deteriorating water quality, migration corridors barriers, sedimentation, greenhouse gas emission and biodiversity loss are environmental impacts of hydropower projects. Appropriate mitigation measures are required to sustainably generate hydropower. These are also discussed in the paper
\end{abstract}

Keywords: Environmental impacts; Hydropower; Mitigation measures

\section{Introduction}

Hydropower is one of the most efficient power generation technologies, which are carbon free and use inexhaustible resources to produce the energy. The prime driver is the force of gravity and the water used to drive this power is non-destructive [1]. According to Yüksel [2] hydropower do not pollute the air we breathe in the way that the energy source does not produce any air pollutants. Unlike thermal power plants for example, there are no gaseous of fly ash emissions emitted during the production. The fact that hydropower often replace fossil-fired generation, it can therefore also be said that it is reducing the problem with acid rain and smog $[1,2]$. Despite all these advantages hydropower plants have, there may also be negative impacts. Lately the impact on the ecological aspects from the power plants has received attention. In the report from World Commission on Dams [3], it is stated that dams will have effects e.g. on the terrestrial ecosystem and biodiversity, the flow regime, migration of aquatic organisms, and can cause emissions of greenhouse gases. Bratrich [4] states that hydropower affects the flow regime, migration of organisms and transport of nutrients and sediments.

Abbasi [1] claim that hydropower plants causes major ecological impacts in all of the four different habitats, which are associated with the projects; the estuary into which the river flows, the downstream reaches of the dammed river, the reservoir catchment and the artificially created lake. Different research works from all corner of the world's reported considering the negative effects of hydropower on the environments and calls for the importance of adopting of appropriate mitigation measures $[5,6]$. Therefore, to ensure sustainable development, various mitigation and enhancement measures have to be integrated at the early stages of project planning. Furthermore, appropriate mitigation measures not only for hydropower development that is newly planned and implemented in future, but also for the refurbishment and upgrading of hydropower plants which are currently in operation, need to be devised. The purpose of this paper is to review the impacts of hydropower on the environment and alternative mitigation measures.

\section{Impacts of Hydropower}

The hydropower projects have several impacts on the environment. Water quality decline is one of the impacts of hydropower and water quality may be affected around a hydropower plant [7]. Water discharged from a reservoir can be of a different composition to the water that is flowing into a reservoir 
[8]. The other impacts of hydropower plant are migrations barriers. Hydropower dams impede the flows of rivers and thereby affect the habitat of various aquatic lives [9]. Migratory animals require different environments for their different phases of their life cycle. Different stages are reproduction, production of juveniles, growth and sexual maturation. These different stages take place in different environments for different fishes [6]. Even if hydropower is a renewable energy source it is not an energy source without GHG emissions [5]. Greenhouse gas emissions can occur at three different phases hydropower plant (the construction, the operation and maintenance and the decommissioning of the plant). During the construction phase the emissions comes from the production and transport of the materials needed for the construction and from the work equipment.

In the second phase, the operation and maintenance, the emissions can come from e.g. heating or cooling systems and transportation for maintenance work [5]. Hydropower project also leads to sedimentation [10]. The natural carried sediment from the usual natural flow will be negatively affected $[5,10]$. Bergengren [6] states in their report that when constructing a dam or hydropower plant, changes in the hydrological regime will follow. IPCC suggest the same thing and claim in their report that changes in the hydrological regime is a significant impact from the hydropower plant. They argue that due to a hydropower plant there will be changes in water level, timing and temperature, which will affect the surrounding terrestrial and aquatic ecosystem [8]. The other biggest threats from hydropower projects are the loss of biodiversity and ecosystems that provides services that we cannot live without. The loss of valuable vegetative community types and loss of wildlife and habitats are resulted from land clearance and removal of natural vegetation [11].

\section{Mitigation Actions}

The purpose of environmental mitigation requirements at hydroelectric projects is to avoid or minimize the adverse effects of development and operation. Among the mitigation actions dam removal is becoming a more frequently used management option all around the world. Dam removal is taking into consideration for old dams in need of renovation or small dams that are no longer used or have lost most of their reservoir capacity. Another point of view is that dams and the reservoirs have many ecological effects; the disruption of the movement of different organisms is probably the most important reason for dam restoration. Thereby, dam removal makes it possible for fish migration and fish species to shift from lentic to lotic, which in turn have the ability to migrate and reproduce in free-flowing water [12]. Flow Regulations is also one the promising action for mitigating negative impacts of hydropower projects. In order to make the use of hydropower plants more compatible with the natural life of rivers, a minimum flow must be released so as to assure the preservation of the hydrological continuity of the river and the consequent conservation of natural habitat and ecological life [13]. Minimum flow release means that you allow some flow below a hydropower plant with the dual aim of maintaining current water ecological conditions and partly also for aesthetic or recreational purposes on a watercourse distance, which would mostly had remained drained otherwise [13].

The problem with sedimentation in the surroundings of the hydropower plant can be mitigated by constructing sedimentation measures such as the construction of small-scale weirs to trap the sands and the particles that later can be manually removed [14]. A direct approach to reduce the accumulation of sediment is to mechanically remove the sediments by periodic dredging [7]. Biotope Adjustments is also other migration action. Adjusting the biotope through the creation of greater environmental heterogeneity, by using such as habitat adjusting measures, the biological diversity of the benthic fauna will be strengthened [15]. Constructing migratory corridors are other mitigation actions for migrating animals. To facilitate for the migration of the species in the streams it is therefore desirable to construct corridors [11]. Fish friendly turbine technology is an emerging technology that provides a safe approach for fish passing though the turbines by minimizing the risk of injury or even death [8]. Aquatic animal Plantations is also other mitigation measures to reduce the negative effects of hydropower projects on the aquatic animals. Artificially manage the fertilization, hatching, growth and release of aquatic animal's especially salmonid fish [16]. To introduce planted fish to protect endangered species or reintroduce species that have disappeared may be of great benefit to the environment and the biodiversity [16].

\section{Conclusion}

From the above review, it is known that hydropower project have impacts on the environment. Change in hydrological flow regimes, deteriorating water quality, migration corridors barriers, sedimentation, greenhouse gas emission and biodiversity loss are environmental impacts of hydropower projects. Dam removal, flow regulations, biotope adjustment, fish plantation, sedimentation measures, constructing migration corridors and fish friendly turbine are alternative action for mitigating the negative impacts of hydropower projects on the environment [17]. Therefore, to meet the increasing demands energy and ensure sustainable development, various mitigation and enhancement measures have to be integrated at the early stages of project planning. Furthermore, appropriate mitigation measures not only for hydropower development that is newly planned and implemented in future, but also for the refurbishment and upgrading of hydropower plants which are currently in operation, need to be devised.

\section{References}

1. Abbasi T, Abbasi S (2011) Small hydro and the environmental implications of its extensive utilization. Renewable and Sustainable Energy Reviews 15(4): 2134-2143.

2. Yüksel I (2010) Hydropower for sustainable water and energy development. Renewable and Sustainable Energy Reviews 14(1): 462469. 
3. World Commission on Dams (2000) Dams and Development-A new framework for decision making. No. November. Earthscan Publications Ltd, UK.

4. Bratrich C, Truffer B, Jorde K, Markard J, Meier W, et al. (2004) Green hydropower: a new assessment procedure for river management. River Research and Applications 20(7): 865-882.

5. Kumar A, Schei A, Ahenkorah A, Caceres Rodriguez R, Devernay JM, et al. (2012) Hydropower. In IPCC Special Report on Renewable Energy Sources and Climate Change Mitigation. Inter governmental Panel on Climate Change, Cambridge, England.

6. Bergengren J, Näslund I, Kling J (2013) Hydroelectric impact on aquatic ecosystems. Maritime and Water Authority, Gothenburg.

7. Bergkamp G, Mccartney M, Dugan P, Mcneely J (2000) Dams, Ecosystem Functions and Environmental Restoration.

8. Edenhofer O, Pichs Madruga R, Sokona Y, Seyboth K, Matschoss P (2012) Renewable energy sources and climate change mitigation: special report of the Intergovernmental Panel on Climate Change. Intergovernmental Panel on Climate Change, New York, USA.

9. Ghosh TK, Prelas M (2011a) Energy Resources and Systems. Vol 2, Springer, Netherlands.
10. Azarpour A, Suhaimi S, Zahedi G, Bahadori A (2012) A Review on the Drawbacks of Renewable Energy as a Promising Energy Source of the Future. Arabian Journal for Science and Engineering 38(2): 317-328.

11. Anjaneyulu Y, Valli M (2007) Environmental Impact Assessment Methodologies $\left(2^{\text {nd }} E d n\right)$. BS Publication, India.

12. Lejon A, Malm Renöfält B, Nilsson C (2009) Conflicts Associated with Dam Removal in Sweden.

13. Erlandsson K (2008) Use of scenarios for strategic environmental assessments for hydropower installations. Ph.D. thesis, Swedish University of Agricultural Sciences, Sweden.

14. International Energy Agency (2011) Technology Roadmap Hydropower. Paris, France.

15. Hovsenius G, Nilsson C, Leijon M (2002) Water Power in Sweden: An Fact Report in the IVA Project Energy Frameworks Sweden in Europe. Eskilstuna, Sweeden.

16. Agriculture Department (2014) Fish release.

17. omraden/djur/olikaslagsdjur/fiskarochandravattenbruksdjur/ utsattningavfisk.4.5586fdf512e8fc79a8480002288.html.

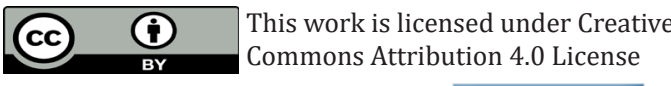

To Submit Your Article Click Here: Submit Article

DOI: $10.32474 /$ CIACR.2018.02.000133

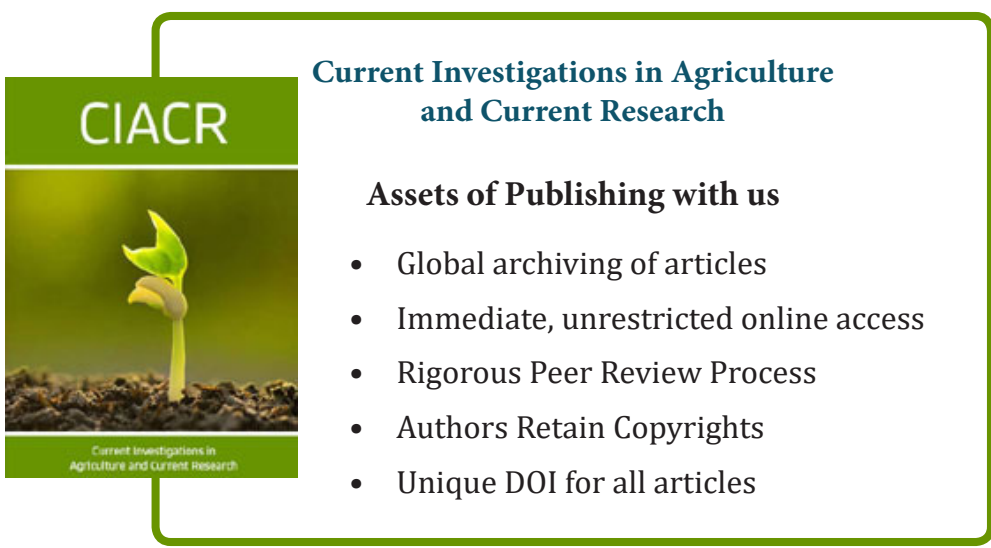

